\title{
Using Sound in Teaching Reading in Early Childhood Education
}

\author{
Hanna Onyi Yusuf \\ Faculty of Education, Ahmadu Bello University, Samaru - Zaria, Nigeria \\ Email: hannayusuf@yahoo.com \\ Agnes Ovayioza Enesi \\ Faculty of Education, Ahmadu Bello University, Samaru - Zaria, Nigeria \\ Email: ovayi@yahoo.com
}

\begin{abstract}
Early childhood is as charming as ever. It is an age of imagination and fantasy. Therefore, it is natural that education at this stage should develop the child's imagination through literacy materials such as folk-tales, rhymes and songs etc. This paper is therefore intended to enthuse to the psychological view that children's success in life depends on the preparation they receive when younger. The paper upholds the view that a good preparation of children for life entails giving them the ability to read and write. The importance of literacy is measurable. Literacy is instrumental to the attainment of success of individuals in both career aspirations and quality of life. It is fundamental for learning in school. It impacts on individuals the ability to participate in society and understand important public issues. It also provides foundation upon which skills in the labour industry are built, etc. The paper concludes that literacy, which should start from infancy, could be better taught using the phonics methodology. This is because, in early childhood, education should involve more of playing, singing, clapping, etc, and that is the focal objectives of phonics method. This should be so to support the idea that literacy should not be boring but enjoyable especially as early as infancy, because it is a panacea for achieving life's goals.
\end{abstract}

Index Terms—sound, literacy, early, childhood, education, phonics, pronunciation

\section{DEFINITION OF LITERACY}

Traditionally, it is considered as the ability to use written language actively and passively. Some definitions of literacy see it as the ability to read, write, spell, listen, and speak. Since the 1980's, some have argued that literacy is ideological which means that it always exits in a context, in tandem with the values associated with the context.

Literacy is a concept claimed and described by a range of different theoretical fields. The United Nations Education, Scientific and Cultural Organisation (UNIESCO) defines literacy as the ability to identify, understand, interpret, create, communicate, compute and use printed and written material associated with varying contexts. Literacy involves a continuum of learning in enabling individuals to achieve their goals to develop their knowledge and potential and to participate fully in their community and wider society.

Wenner (2009) Hannon (2008), Moll and Harste (1994) said literacy has for instance expanded to include literacy in information technology etc. The definition of literacy has therefore become dynamic evolving, and reflects the continual changes in our society. Moll (1994) added that literacy is not isolated in bits but in students' growing ability to use language and literacy in more broader activities.

Literacy is also the ability to make and communicate meaning from a variety of contextual symbols. Within various levels of development activity, a literate person can derive and convey meaning, and use their knowledge to achieve a desired purpose or goal that requires the use of language skills, spoken or written. A literate person mediates his/her world by deliberately and flexibly orchestrating meaning from one knowledge base and applying it to another knowledge base. For example, knowing that letters symbolize sounds, and that those sounds make sense to which the reader can attach meaning, is an example of the cognitive orchestration of knowledge a literate conducts.

Some have argued that the definition of literacy should be expanded. For example, in the United States, the National Council of Teacher of English and the International Reading Association have added "Visual representing" to the traditional list of competencies. Similarly, in Scotland, literacy has been defined as the ability to read, write and use numeracy to handle information, to express ideas/opinions, to make decisions and solve problems, as family members, workers, citizens and life-long learners.

A basic literacy standard in many societies is the ability to read news papers. Increasingly, communication in commerce or society in general requires the ability to use computers and other digital technologies. Since the 1990s, when the internet came into wide use in the United States and later to other parts of the world, some have ascerted that the definition of literacy should include the ability to use tools associated with the internet. Similarly, other scholars 
have it multimedia literacy, computer literacy, information literacy, etc. On the whole, it is argued that literacy includes the cultural, political and historical contexts of the community in which communication occurs.

\section{IMPORTANCE OF LITERACY}

- Literacy is crucial to the success of individuals in both their career aspirations and their quality of life.

- It is more than a basic reading ability, but rather an indication of how adults use written information to function in society.

- Strong literacy skills are closely linked to the probability of having a good job, decent earnings, and access to training opportunities. Individuals with weak literacy skills are more likely to be unemployed, or if employed, to be in jobs that pay little or that offer poor hours or working conditions.

- Literacy is fundamental for learning in school. It has an impact on an individual's ability to participate in society and understand important public issues.

- It provides the foundation upon which skills needed in the labour market are built. A population's literacy skills also have a bearing on how well a country performs economically.

- Literacy enriches children's language. Children are affected by the language they hear and they gradually learn to approximate the variety spoken by those around them. Chomsky (1972) examined children's language in relation to the amount of reading done by them. He found out that children who are read to and who read more on their own have a greater knowledge of complex language structures than children that read less and are hardly read to.

- Literacy also facilitates learning to read. Lesslie (2007) found that children that learned to read early had been read to and had someone who answered their questions.

- It nourishes the child's imagination. Children that experience literacy are provided a rich source of idea for imagination.

They familiarize themselves with possibilities as they try out roles from literature. Young children can have valuable experiences with books if someone carefully guides them through these experiences which tend to develop children's minds, excite their curiosity, and make them interested in reading on their own.

\section{LITERACY IN EARLY CHILDHOOD}

The six years of primary school are crucial to the educational development of the child. This is when the child learns to read independently. It is also the time when he is likely to establish reading habits that will prevail through secondary school and adult life. A good primary school reading syllabus should provide for both the development of reading skills and the encouragement of reading for pleasure. Ideally, literacy in this early stage cuts across the entire course of study. There is need to take note of introducing literacy/literature to children since it involves the development of appreciation and taste.

Many Nigerian children now have more contacts and interests than their counterparts some decades ago. This is because, the television and other electronic devices have brought the World to their living rooms, and they watch and listen to various literacy programmes meant for their age and those of adults too. It is necessary to point out here that the home has a great contribution to make not only to the child's personality but also to his cognitive development, through child stimulation. Child stimulation starts as early as the child is born. The mother must not delay talking to the infant, thinking he/she is too small to understand. As soon as the senses begin to function, learning starts. That is why the care giver must start right from birth to appeal to all the senses through talking, singing, patting, decorating the baby's cot, etc. As the baby grows, other adults and children should be encouraged to play with the child. Through this socialization process, children learn to manifest such characteristics as confidence, competency cooperation and friendship. Yarrow, Rubinstein and Pederson (1995) in their study of "Childhood Education" added that toys and a variety of play materials significantly affect infant development in such areas as reading and grasping, and exploratory behaviour. Thus, the earlier the opportunities are provided for exploration of varied objects, spaces and places and, the stronger the development of curiosity, the better the inquisitiveness and questioning.

The role of the teacher of young children is to co-operate with nature in helping each child develop his/her potentials. The teacher, whether the indirect (parents/other adults) or the direct (the certified teacher) needs an understanding of some of the principles of child development as they are applied in traditional and modern education. Unoh (1983) argued in favour of this ascertion and says that education is the art of teaching and training the child to enhance his physical, intellectual, moral and spiritual development.

A generally acknowledgement need in Nigeria today is for skilled manpower, and the crucial question is how that supply can best be achieved (Adams 2008). Academically-oriented curricular provide the base for the development of this skilled manpower. This is done in various stages of development of the child, from nursery to the higher education and from childhood to adulthood.

The primary intentions are to introduce concepts and techniques that develop abilities, attitudes, skills and understanding that make youths and adults occupationally competent participants in the changing economic life of the nation, regardless of the level at which a person learns in school (Yusuf, 2010) 


\section{EARLY CHILDHOOD EDUCATION}

Early childhood education is the organized practice of educating those who are in early childhood which is one, one of the most vulnerable stages in life. According to the National Association for the Education of Young Children (NAEYC), it spans the human life from birth to eight years.

Early childhood, according to Bear and Johnston (2008), often focuses on children learning through play. According to UNESCO's Early Childhood Care and Education Unit (ECCE), early childhood is defined as the period from birth to about eight years old which is a time of remarkable brain development. These years lay the foundation for subsequent learning.

Templeton (2004) opined that researchers in the field and early childhood educators both view the parents as Early Childhood Education takes many forms depending on the beliefs of the education or parents. Much of the first two years of life are spent in the creation of a child's first "sense of self" or the building of a first identify. This is a crucial part of children's make-up how they first see themselves, how they think they should function, how they expect others to function in relation to them. For this reason, early care must ensure that in addition to employing carefully selected and trained caretakers, programmes policy must emphasize links with family, home culture, and home language; meaning that caregiver must uniquely care for each child using developmentally appropriate practice care to support families rather than a substitute for them. Yusuf (2010) added that if a young child doesn't receive sufficient nurturing, nutrition, parental/caregiver interaction, and stimulus during this crucial period, the child may be left with a developmental deficit that hampers his or her success in preschool, kindergarten/nursery, and beyond. Therefore, children must receive attention and affection needed to develop in a healthier manner.

\section{A. Developmental Domains}

There are five different developmental domains of children which all relate to one another and they are easily refered to as the SPICE of life:

- Social - refers mostly to the ability to form attachment, play with others, co-operation and sharing, and being able to create lasting relationship with others.

- Physical - Development of five and Gross motor skills

- Intellectual - The process of making sense of the World around them.

- Creative - The development of special abilities creating talents. Music, Art, Writing, Reading, and singing are all ways for creative development to take place.

- Emotional - Development of self-awareness, self-confidence, and coping with feelings as well as understanding them.

\section{B. Objectives of Early Childhood Education}

The objective of early childhood education according to the National Policy on Education (2007) is to

- effect a smooth transition from home to the school

- prepare the child for the primary level of education

- provide adequate care and supervision for the children while their parents are at work, farms or market, etc.

- inculcate social norms in them.

- inculcate in the child the spirit of inquiry and creativity through the exploration of native, and the local environment, playing with toys, artistic and musical activities, etc

- teach co-operation and team spirit

- teach the rudiments of numbers, letters, shapes and colours, through play.

- Teach good habits, especially good health habits

According to Yusuf (2010), these objectives are laudable, but a lot has to be done to achieve them. For example, secondary school children in Nigeria are in critical stage of their development. She therefore stressed that they should be engaged in formulating a self-concept, establishing an identity, developing occupational skills and awareness, and encountering challenges in the world of education achievement. Educators must provide the right and timely assistance to enable the child develop the occupational competence that will make him/her viable in the society (P.47-49).

\section{SCOPE OF CHILDREN LITERACY}

The scope of children's literacy includes stories of real people of today and yesterday, realistic fiction tales, stories of animals, machines, and interventions, stories dealing with the world of nature, stories depicting everyday experience of children, folklore and books of poetry. Literacy materials necessary for this age group are examined below:

Folktale/Story Telling

The folktale is the most important and popular form of oral literature in Africa through which traditional customs such as those related to inheritance are recalled. The tales involve ethical teaching through which the child learns the values and norms of his/her society, and he/she thus grows up to fit properly into it. To understand more of African culture, one must know the folktale of his/her area because it illustrates, the people's perception of the world and their 
environment (Okunade, 2005). It is therefore important to incorporate story telling into primary school curriculum because of its immense advantages. Knowledge and wisdom are derived by the child from stories by the child.

Picture Books and Picture Story Books

According to Okunade (2005), these visual art forms provide children with their first experiences in art and literature. Books in this category cover a wide range of topics, both factual and otherwise and these include books made of fabric, cardboard, picture books. In the story is told through illustration. The first time through an adult, possibly a teacher, and the children look at the book together, discovering the story and telling it to each other. Later, the children can read it to other children. It is essential to say here that, such books contribute to oral language development, serve as stimulus for creative story telling and develop a sense of story long before a child can read.

\section{Poetry, Rhymes, Songs}

Young children respond early and naturally to the language of poetry for it usually is a shared experience with the competent teacher. Poetry itself appeals to both young and old because of its elements like imagery, rhythm, metre, form and other aesthetic elements.

Rhymes are an indispensable part of a child's introduction to literature. Humorous incidents and characters are presented in verses with pleasurable rhythm and rhyme to delight the ear.

Children love to clap, tap, hop and to imitate objects and animals where rhythms lend themselves to such movement and actions. When a teacher reads aloud, he/she enjoys himself/herself and also create a shared experience between himself and the children.

Children could be made to perform some of the actions involved in the poem below:

My head, my shoulder

My knee, my toes

My head, my shoulder

My knee, my toes

My head, my shoulder

My knee, my toes

All belongs to God...

\section{LITERACY IN THE $21^{\mathrm{ST}}$ CENTURY}

One needs simply to reflect on the nature of the communication being practised in reading this paper to understand the form of evolution in our understanding of literacy. We no longer rely on an individual or a small group of individuals to convey information.

Traditional news outlets are battling for popularity with blogs, forums, twitter, and instant messaging aka sms. During the Iranian Revolution in June 2009, such news sources were so valuable that the United States' state department officials asked Twitter to postpone site maintenance which would stop the flow of information. This is an aspect of literacy, computer and information technology literacy.

This idea has forever changed the landscape of information access and it is integral in an understanding of literacy as a practice in the $21^{\text {st }}$ Century. It is no longer sufficient to consider whether a student can read and write, but it is necessary to consider more meaningful aspects of literacy in education and in society as a whole, if we are to complete the transition we are in, from a society in which communication was never possible on the level of many to many, to one in which it is.

\section{TEACHING LITERACY}

There are many approaches to teaching literacy. Each is shaped by its informing assumptions about what literacy is and how it is best learned by students. Phonics instruction, for example, focuses on reading at the level of the word. It teaches readers to attend to the letters or groups of letters that make up words

A common method of teaching phonics is synthetic phonics, in which a novice reader pronounces each individual sound and blends them to pronounce the whole word.

Another approach to phonics instruction is embedded phonics instruction, used more often in whole language reading instruction, in which novice readers learn about the individual letters in words on a just-in-time, just-in-place basis that is tailored to meet each student's reading and writing learning needs. That is, teachers provide phonics instructions opportunistically, within the context of stories or student writing that feature many instances of a particular letter or group of letters. Embedded instruction combines letter-sound knowledge with the use of meaningful context to read new and difficult words.

\section{A. Teaching Literacy Using Phonics Method among Children}

Phonics is a method for teaching speakers of English to read and write that language. It involves learning how to connect the sounds of spoken English with letters or groups of letters. For example, the sound /k/ can be represented by (c), (ck), (ch) or (q) spellings, and teaching them to blend the sounds of letters together to produce approximate pronunciation of unknown words. 
Phonics is a widely used method in teaching to read and decode words. Children learn to read with phonics usually around the age 5 and 6 . Teaching literacy using phonics requires pupils/students to learn the connections between letter patterns and the sounds they represent. Phonics instruction requires the teacher to provide pupils with a core body of information about phonics rules, or patterns.

\section{B. Basic Rules of Phonics}

\section{Sub-lexical Reading}

This involves teaching reading by associating characters or groups of character with sounds or by using phonics learning and teaching knowledge. It is sometimes argued to be in competition with whole language methods for instance "apple", spelt as $/ \mathrm{a} /+/ \mathrm{p} /+/ \mathrm{p} /+/ \mathrm{l} /$ and $/ \mathrm{e} /$ could represent the letter $/ \mathrm{a} /$, while the drawing/painting of something that looks like a "king" or "lion" could be used to represent letters $/ \mathrm{k} /$ and $/ \mathrm{l} /$ respectively. So, anytime the child sees letter /a/, /k/, and /// etc, these words - apple, king and lion come to his senses. As he starts to read on his/her own, wherever he sees these words, he/she won't refer to you for its pronunciation. He/she has gained a substantial competence in its pronunciation and or orthography.

Lexical Reading

This involves acquiring words or phrases without attention to the characters or groups of characters that compose them or by using whole learning and teaching methodology.

Alphabetic Principle

English spelling is based on the alphabetic principle. In an alphabetic writing system, letters are used to represent speech sounds or phonemes. For example the word "pat" is spelled with three letters - p, a, and teach representing a phoneme respectively - /p/, /ae/, and /t/.

The spelling structures for some alphabetic languages, such as Spanish are comparatively orthographically transparent because there is nearly a one-to-one correspondence between sounds and the letter patterns that represent them. English spelling is more complex with a deep orthography, because it attempts to represent the 40+ phonemes of the spoken language with an alphabet composed of only 26 letters and no diacritics. As a result, two letters are often fused together into groups that represent distinct sounds referred to as digraphs.

English has absorbed many words from other languages, it therefore remains imparative to teach these words, its pronunciation, from early childhoods, at a time the Language Acquisition Device (LAD) is still flexible (Chomsky 1972). Hence children can be taught the following simplest forms: /c/, /a/, /t/ is cat.

However, "C" can be pronounce as $\mathrm{k}$, ch, ck etc, while "a" is ae, ei etc as in "apple", able, ant, ape, etc. The same process is replicated in the /t/ sound and others.

Although the patterns are inconsistent, the teacher should make effort to pronounce these sounds as impeccable as possible.

\section{Vowel Phonics Patterns}

Short vowels There are five of them - a, e, I, o, u. They produce the sounds /ae/ as in cat, /e/ as in egg, /i/ as in sin, sit, /o/ as in hot, and $/ \mathrm{u} /$ as in cup. The term short vowel does not really mean that these vowels are pronounced for a particular short period of time, but they are not dip thongs like the long words and the teacher should take not of this.

Long vowels are homophonous with the names of simple letter vowels, such as /ei/ in body, /i/ in metre, /a/ in tiny, /ou/ in broken, and /ju/ in humour. These sounds come as /ei/, /I:/, /ai/, or /au/ and /ju/ respectively.

In the classrooms, teachers should teach children that a long vowel is realizable in the following words: say, hey, why, kite, fight, bounce, croak, fly, write, owl, etc.

Vowel digraphs are those spelling patterns wherein two letters are used to represent the vowel sound. The ai in sail is a vowel digraph.

\section{Consonant Phonics Pattern}

This is where children often find it difficult because alphabets here are often confusing, for example the consonant /c/ can sound as $\mathrm{k}$, ch and ck. If one is not careful, as a teacher, the children/pupils will pronounce knife wrongly, the / $\mathrm{k} /$ there will mislead them because of the earlier assumption. There is need to explain exceptions or simply do not use such confusing words initially or at the beginning. Start from the simple and as children mature such complex cases can be introduced gradually.

\section{Different Phonics Approaches}

Synthetic Phonics method was made popular by Diaz (2009).

This is a method to teach phonics to children when learning to read. This method involves examining every word individually as an individual sound and then blending those sounds together. For example "boy" would be read by pronouncing the sounds for each spelling and then blending those sounds orally to produce a spoken word that sounds as this [boiz] (Diaz,2009). The goal of synthetic phonics instruction is that pupils identify the sound -symbols and blend the phonemes automatically. Also, what is inferred here, is to teach pupils the sounds of the language, (ie) instead of the traditional ABC..., the teacher should tell these children that the letter/alphabet is pronounced as /ae/ sound and words such as - apple, axe, ant, arm, etc, can be realized from the sounds therefore, anywhere the child sees "a", he'she knows that the sound is /ae/, and so on. 
The same is done in letters B,C and D. For instance, letter B is pronounced as (bu) as can be seen in - boy, bag, bus, bool, bird, band, etc. Letter C is pronounced as "k" as in - cake, etc.

Analytical Phonics

Here, children analyze sounds symbol correspondences, such as the /oi/ sound in 'boy'. Consonant blends are taught as units for example, in the word "chief" the ch would be taught as a unit/sound.

Embedded Phonics

This is the type of phonics instruction used in whole language programmes. Although phonics skills are deemphasized in whole language programmes, some teachers still put it to practice in the context of literature. Short lessons are included based on phonics elements that pupils are having problem with, or on a new or difficult phonics pattern that appears in a class reading, homework/assignment. The focus on meaning is gradually maintained, but the mini lesson provides some time for focus on individual sounds and the symbols that represent them. According to Borowsky (2007), embedded phonics differs from other methods in that the instruction is always in the context of literature rather than in separate lessons, and the skills to be taught are identified opportunistically rather than systematically. Owing to the shifting debate over time, many school systems have made major changes in the method they have used to teach early reading. Today, most teachers combine phonics with the elements of whole language that focus on reading comprehension.

Yusuf (2004) advocated for a comprehensive reading programme that includes several different sub-skills. She called these a combined approach which gives a balanced literacy. Proponents of various approaches generally agree that a combined approach is important. A few Stalwarts favour isolated instruction in synthetic phonics and introduction to reading comprehension only after children have mastered sound-symbol correspondences. On the other side, some whole language supporters are unyielding in arguing that phonics should be taught little, but majority of authors endorse the phonics ideas; such as Bell, Chomsky, Crystal, and Torres, among others.

\section{E. Tips on Using Phonics to Teach Literacy: Reading}

In guiding pupils to understand what is taught to them in the classroom, the teacher would need to take the following steps as suggested by Oyetunde (2009).

Step 1: Stating clear objectives

The teacher should state his/her objectives in behavioural terms. He/she should then design learning activities that match each of the stated objectives in accordance with the age of the learner. For instance, a phonics lesson might have these objectives: (a) the pupil/student will demonstrate an understanding of the sounds by answering questions posed (b) pupils will be able to use two or more sounds and pronounce them accordingly. They can also be asked to combine sounds to form meaningful words.

Step II: Pre-Pronunciation practice

The teacher activates the pupil's background experience and guides them through a list of words as he/she pronounces them correctly, then learners repeat after the teacher.

Step III: Pupils read one after another

After the necessary pronunciation practice, the teacher may ask the pupils to point at the words, pronouncing them correctly. If a pupil cannot read the words on his/her own, then more practice still needs to be done.

Step IV: Evaluation/Testing

This is the stage for evaluating the pupil's mastery of some of the reading skills/ pronunciation drills the teacher has tried to inculcate. In Nursery/Primary School, the teacher can ask the learners to pronounce the words or write them in their books respectively. Learners may be asked to combine certain sounds to form a word. For example, the teacher may pronounce some sounds such as C, as "k", A as /ae/, and he/she then tells them to generate the correct letters for this word.

Step V: Follow-up Activities

Whatever the teacher does to encourage pupils or students to use the skills developed during the lesson is useful. For instance, they could be asked to attempt using some of the difficult words that could not be tested during the lesson. This might give the pupils further practice with the use of pronunciation drills to further develop and enhance the skills.

Through pronunciation activities, the child can be taught to develop skills based on interaction with practical materials such as apple, egg, cat, ant etc with the teacher serving as the stimulus.

\section{CONCLUSION}

Early childhood education is very significant in the growth and development of the child. Relevant education at this level will lay a solid foundation on which future efforts of the child as a useful member of this community will depend. It is therefore, recommended here that phonics methodology be employed in teaching these children. Instead of teaching them how to read and master the 26 alphabets - ABC-Z, it is suggested here that the sounds derived from these letters are taught them. For example, the alphabet "A" can be realized in the following words: apple /ae/, arm /a:/ etc. The former is sharp and short while the latter is a long vowel and so are other letters.

Furthermore, the C, Pronounced as "K" can be realized in these words - cake, lace, teach, etc. Emphasis here is and should be laid on the sounds. The teacher should be an authority in phonics so that the children are not misled. There 
are cases where children may be tempted to call/pronounce the word 'chief' as ' $k$ eif' because the teacher has said ' $\mathrm{C}$ ' is pronounced as ' $\mathrm{K}$ '. So, care should be taken in this complex cases in order to guide and direct the learners aright.

Also note that, children are constantly criticized if they cannot say something correctly and this is quite discouraging. Encouragement and praise, if used liberally, go a long way toward helping the child to develop adequate literacy skills.

\section{REFERENCES}

[1] Adams M. J. (2008). Beginning to read. Thinking and learning about print. Cambridge, M.A. M.T Press.

[2] Bear, D.R and Johnston, F. (2008). Word study for phonics, vocabulary, and spelling instruction. Upper Saddle River; New Jersey: Merrill/prentice Hall.

[3] Borowsky, R. and Cimmine, J. (2006). Processing Streams in Basic Reading Processes: Insular Sensitivity to Phonology. PMID

[4] Chomsky, N C. (1972). Sound of English. London Pearson.

[5] Diaz, G., Sanabria; Torres-Mdel, R; Iglesias, J. et al. (2009) ."Changes in Reading Strategies in School age Children”. Journal of Psychology Vol. 12 (2): 441-453. PMID

[6] Hannon, P. (2008). Literacy, home and School: research and Practice in teaching literacy with parents. London: Falmer.

[7] Leslie, L. (2007). Factors that predict success in early literacy intervention. Reading Research Quarterly, Vol. 34. 400-424

[8] Moll \& Harste. (1994). children and sound: A preview in Keene, E.O. \& Zimmerman, S. Mosaic of Thought. Portsmouth, NH: Heinemann.

[9] National Policy on Education. (2007). Lagos: NERDC Press

[10] Okunade. (2005). Books for early beginners. Suggestions to parents and teachers. Ibadan: Evans.

[11] Oyetunde, T.O. (2009). The Teaching of Reading and Writing in junior secondary schools: An appraisal. Nigeria Educational Forum, Vol. 12(1) 43-49.

[12] Rubinstein and Pederson. (1995). Childhood Education. New York; Harper and Row.

[13] Templeton, S. (2004). The vocabulary spelling connection: Orthographic development \& morphological knowledge at the intermediate grades and beyond. Rowley - Mass: Newbury House.

[14] Unoh, S.O. (1983). Reading Improvement in Nigeria as a Multilingual Nation: Problems and Prospects. In Literacy and Reading in Nigeria, Vol. 1, Zaria: Institute of Education, ABU Zaria.

[15] Wenner, M. (2009). The Serious need for Play-in-Education for Children. United States Education for All Summit (E.F.A)2009.

[16] Yusuf H.O. (2010). creating strategic readers using vocabulary instruction. A paper presented at the $23^{\text {rd }}$ Annual Linguistic Association of Nigeria, University of Portharcourt: Nov $29^{\text {th }}-3^{\text {rd }}$ Dec. 2010.

[17] Yusuf, H. O (2004). Language Development Activities as Strategies for improving Reading Instruction. Postgraduate Seminar, Department of Foundation Arts and Social Sciences Education, University of Abuja. December $9^{\text {th }}$.

Hanna Onyi Yusuf is a seasoned Educationist and Administrator with the following qualifications; Nigerian Certificate in Education (NCE) 1984, Bachelor of Education degree (B.Ed) in Language Arts 1987, Master's degree in Teaching English as a second language (M.EdTESL) 1996, Doctor of Philosophy degree (Ph.D) in Curriculum Studies in 2005.

Agnes Ovayioza Enesi has a PhD, M. Ed. and B. Ed. Degrees in Teaching English as a Second Language (TESL) and Language Arts: English. She has teaching experience at the primary, secondary and tertiary levels of Education. For the past 19 years to date, she lectures, supervise B. Ed. Projects, Masters Thesis and Doctoral dissertations in the department of Education, English and Literary Studies of Ahmadu Bello University Zaria. 